\title{
Pedestrian Model for Injury Prediction for Lateral Impact
}

\author{
H. Čechová * \& L. Hynčík \\ New Technologies - Research Centre in the Westbohemian Region, University of West Bohemia, Plzeñ, Czech \\ Republic \\ *Corresponding author:hcechov@ntc.zcu.cz
}

DOI: $10.2478 / v 10158-0007-z$

\begin{abstract}
World-wide statistics still reflect a high percentage of seriously injured pedestrians in the urban areas. The lateral impact is the most common type of traffic accident in towns. This paper describes the validation of a pedestrian model that will be able to assess the type and level of injury. The human model used is rigid body based with realistic biomechanical joints. The human body model is validated for the case of a lateral pedestrian impact using published experimental cadaveric data. Particular body segment trajectories fit into given kinematic corridors. Based on the standard injury criteria the pedestrian model is able to predict life threatening risk.
\end{abstract}

KEY WORDS: Biomechanics, virtual human model, pedestrian impact.

\section{INTRODUCTION}

Walking is the most natural way to get from one point to another. As stated by the European Commission around $17 \%$ of all traffic fatalities in EU countries are with pedestrians. Based on the study (Maňas et al. 2009) pedestrians in the Czech Republic belong to a group of the most at risk vulnerable road users. The above mentioned study also summarizes that pedestrian road accidents are the most frequent in urban areas with a passenger car impact velocity up to $50 \mathrm{~km} / \mathrm{h}$. Pedestrian protection is therefore still an important topic, as is also shown in the study of Obermann \& Kovanda (2009).

In his article, Ishikawa et al. (1993) analyzes possible pedestrian impact scenarios and summarizes that the most frequent accident type corresponds to a lateral impact when a pedestrian is crossing the road.

The limited biofidelity of dummy models and, especially the actual tendency towards human models legalization (Haug et al. 2003) are the driving force for the creation of correct human body models. The aim of this study is to obtain a validated pedestrian model able to give the overall injury analysis and able to serve for the improvement of safety components in means of traffic.

The used human model Robby (Hynčík, 2001) belongs to a family of Human Articulated Rigid Body (HARB) models (Haug et al. 2004) developed on the PAM computational platform (PAM-System, 2009). The model consists of rigid bodies separated into segments connected by biomechanical joints (Robbins, 1983). 


\section{METHOD}

\subsection{External experimental background}

The model is validated using both literature sources (Ishikawa et al. 1993; Kerrigan et al. 2005; Simms \& Wood, 2006; Stammen \& Barsan-Anelli, 2001) involving experiments with PMHS (Post Mortem Human Subject) and dummies, and also, in several cases, using computer simulations of performed tests. As a key source the work of Kerrigan et al. (2005), presenting the detailed description of the experiment with a full-scale pedestrian impact, is chosen.

The pedestrian in the mid-stance phase of a gait cycle is positioned laterally in front of the car. This position is the most characteristic of real pedestrian collisions and, moreover, represents a significant part of the normal gait cycle (Kam et al. 2005). The mid-stance is the period of the gait between the first contact of the front leg (heel strike) and the last contact of the rear leg (toe off) with the ground. It occupies the period from $7 \%$ to $32 \%$ of the gait cycle. The test was realized three times with cadavers and then with a Polar II Dummy with an impact speed of $40 \mathrm{~km} / \mathrm{h}(11 \mathrm{~m} / \mathrm{s})$. The experimental corridors for body segment trajectories scaled to 50 percentile male were established and the head velocity corridors were published. The analysis was focused only on the primary impact which is limited by the first contact of the car and the pedestrian and the head strike to the windscreen.

\subsection{Impact scenario setup}

The original Robby model of an average male (Robbins, 1983) is used. The Robby is $174 \mathrm{~cm}$ tall and he weighs $74 \mathrm{~kg}$. The relative position of the car and the pedestrian is set according to the experiment (Kerrigan et al. 2005). It means that Robby in the mid-stance phase of the gait cycle is standing laterally to the car front with the struck limb in front, see Figure 1. The hands are connected together ahead of the body to restrict their influence on the body kinematics during the crash.
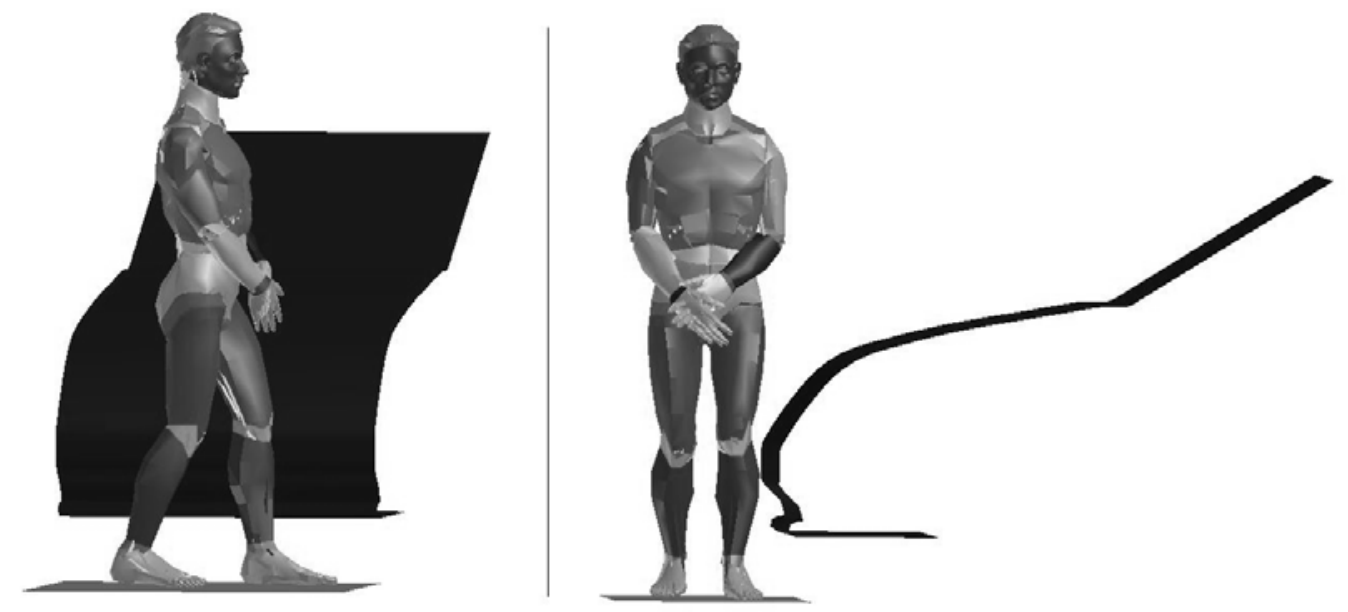

Figure 1: Pedestrian impact model, starting position.

Main car characteristics significantly influencing the seriousness of the pedestrian injury are the mass, the face geometry, and the stiffness. The car profile geometry is adapted from Kerrigan et al. (2005). Despite the precise description of the test itself, the publication lacks detailed information about the car material characteristics. Hence additional literature 
sources (Simms \& Wood, 2006; Stammen \& Barsan-Anelli, 2001) are used to complete the model parameters. The car is modeled as rigid with parameters defined according to a real small car, as reported in Table 1. The Robby's friction coefficient with the ground is set to 0.65 , and with the car structure to 0.25 according to Ishikawa et al. (1993).

Table 1: Table of used car parameters, adapted from (Simms \& Wood, 2006).

\begin{tabular}{|c|c|c|c|}
\hline $\mathrm{m}[\mathrm{kg}]$ & $\mathrm{I}_{\mathrm{xx}}\left[\mathrm{kg} \mathrm{mm}^{2}\right]$ & $\mathrm{I}_{\mathrm{yy}}\left[\mathrm{kg} \mathrm{mm}^{2}\right]$ & $\mathrm{I}_{\mathrm{zz}}\left[\mathrm{kg} \mathrm{mm}^{2}\right]$ \\
\hline 1200 & $425 \mathrm{e}+6$ & $1933 \mathrm{e}+6$ & $2020 \mathrm{e}+6$ \\
\hline
\end{tabular}

A special contact type, including the stiffness characteristics of real car material properties, is used (PAM-System, 2009). It enables the simulation of a more realistic impact behavior of rigid bodies. The used bonnet and windscreen characteristics displayed in Figure 2 are adapted from (Simms \& Wood, 2006).

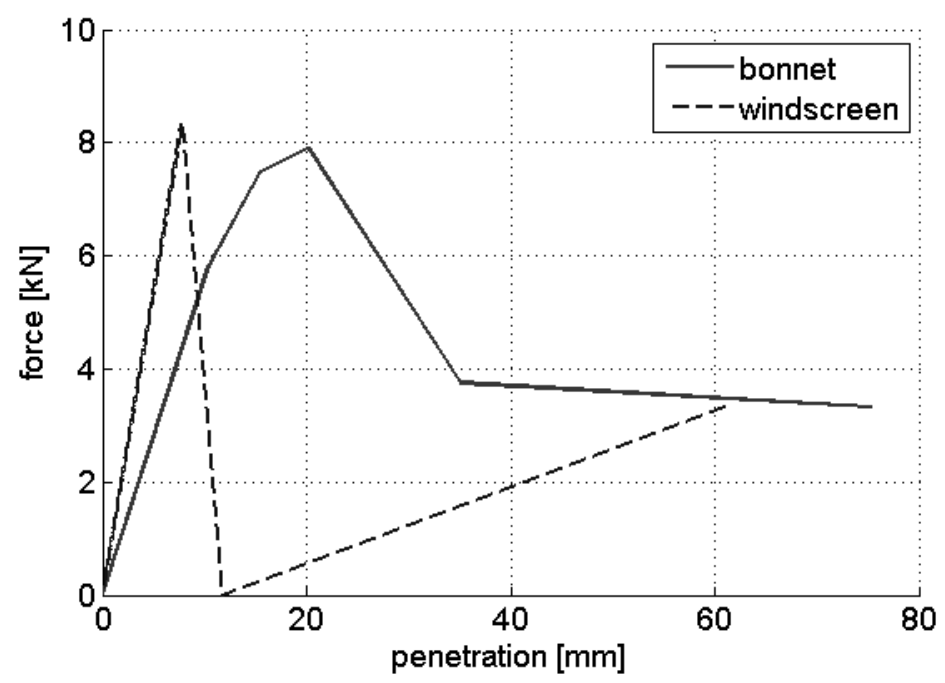

Figure 2: Car force penetration dependency, adapted from (Simms \& Wood, 2006).

\section{RESULTS AND DISCUSSION}

\subsection{Kinematics}

The model kinematics is compared to the published experiments (Kerrigan et al. 2005). The car impacts the pedestrian at knee level, gathers him, and his body slides on the bonnet till the head hits the windscreen; at this instant both the computation and the experiment are stopped. The sequence of the pedestrian motion with the time step 20 ms is shown in Figure 3. The front struck limb tends to turn the model back, which was also proved by Kam et al. (2005). The body parts trajectories in the plane of the vehicle motion lie within the experimental corridors as can be seen in Figure 4 and Figure 5 . The head velocity also fits in the experimental corridors, as shown in Figure 6. 

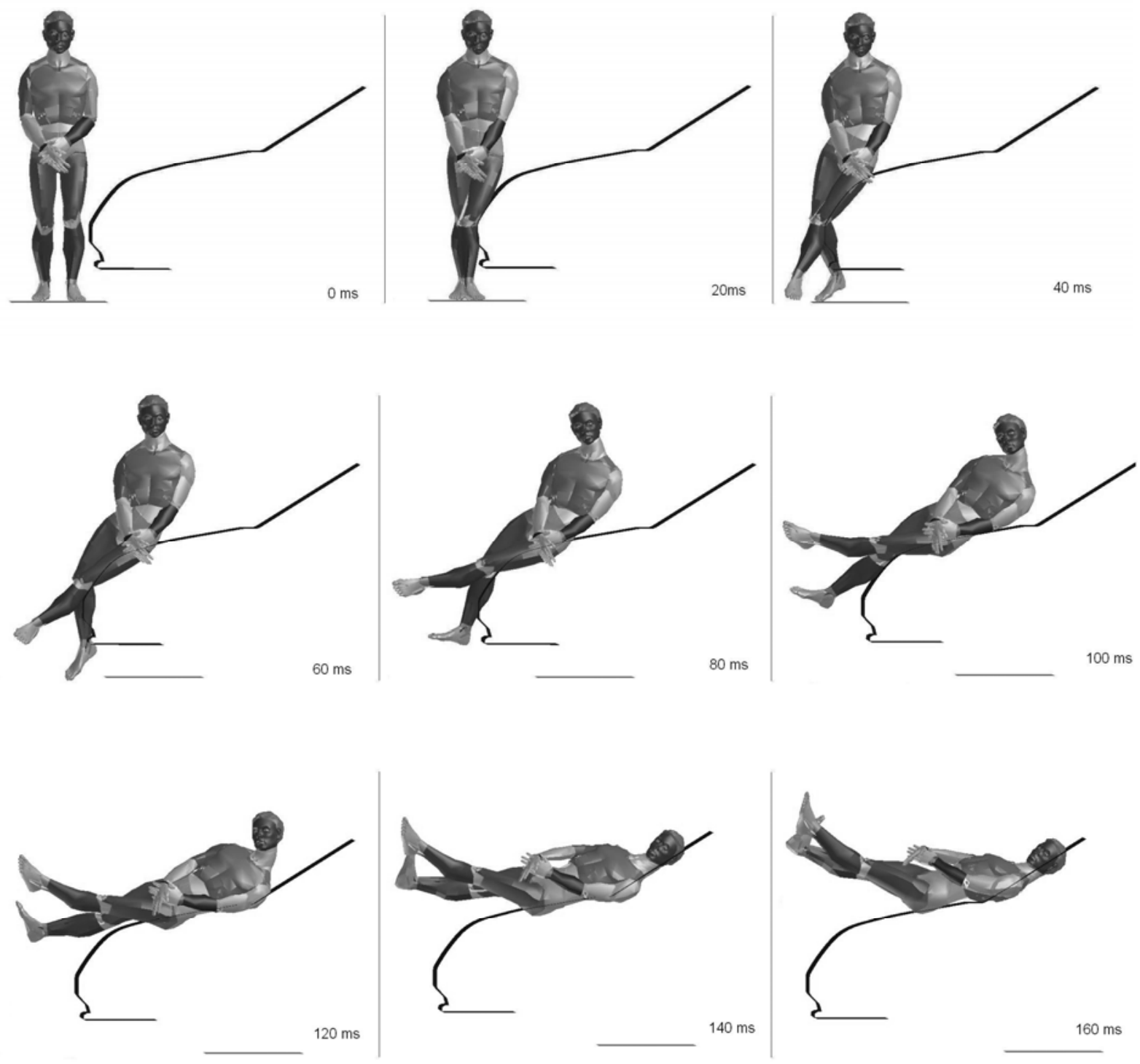

Figure 3: Time sequence of the impact simulation.
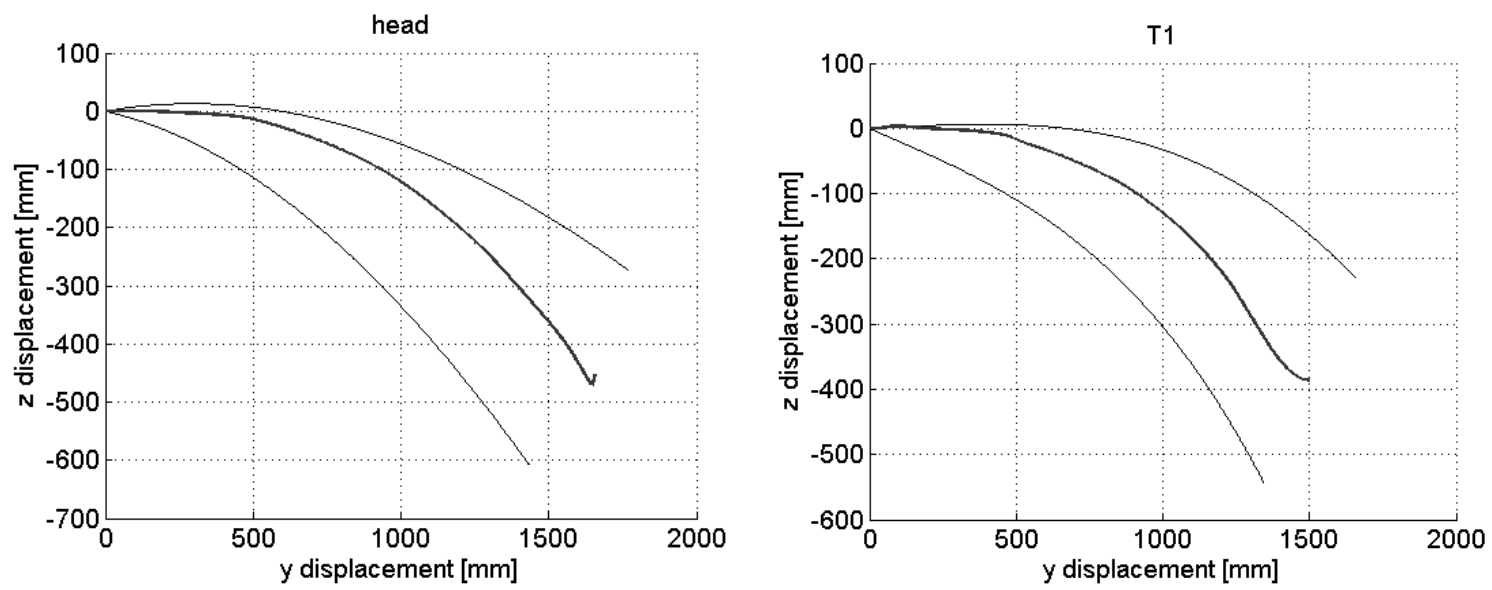

Figure 4: Trajectories of the head (left) and the $\mathrm{T1}$ vertebra (right) in the experimental corridors (black lines) in the mediolateral plane. 

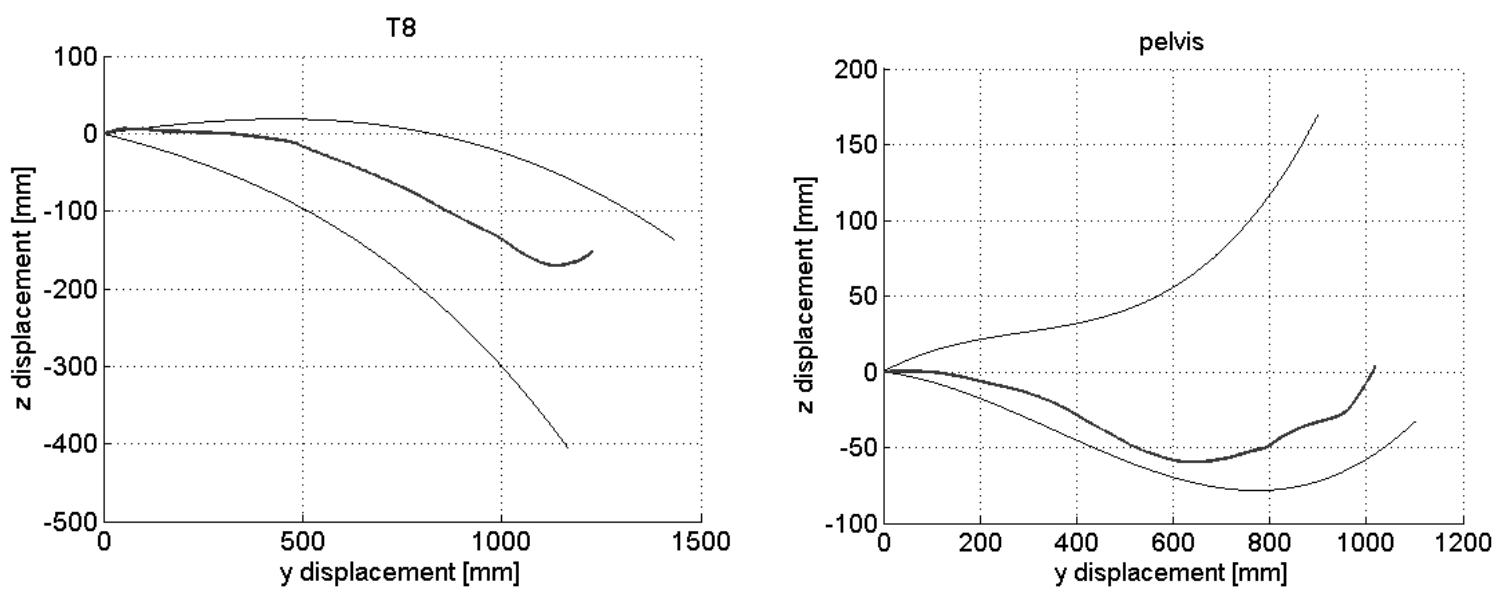

Figure 5: Trajectories of the T8 vertebra (left) and the pelvis (right) in the experimental corridors (black lines) in the mediolateral plane.

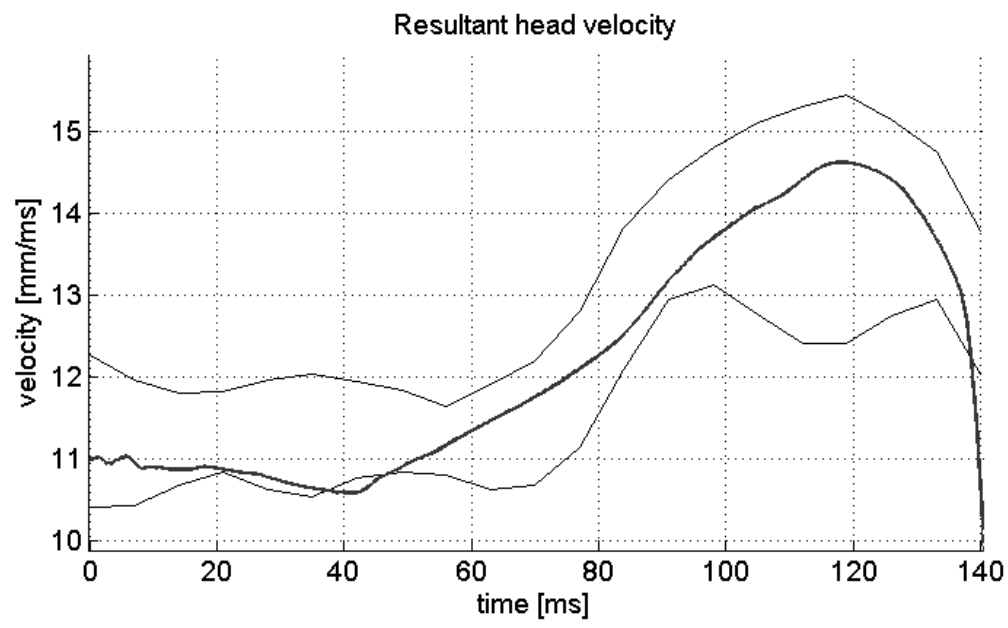

Figure 6: Head resultant velocity in the mediolateral plane in comparison with the experimental corridors (black curves).

\subsection{Injury prediction}

With regard to the successful kinematic model validation a degree of pedestrian risk can be predicted in the sense of directory information. Since Robby is a rigid body based model, injury criteria based on body parts accelerations are used. Despite being highly simplified, they perform an adequate estimation of injury level and their development results from many experiments (Schmitt, 2004).

The standard head injury criterion $\mathrm{HIC}_{36}$ is applied. It performs the $50 \%$ risk of skull fracture that is qualified as AIS $\geq 2$ (Schmitt, 2004). The thorax injury is estimated using the 3ms criterion indicating the $25 \%$ risk of AIS $\geq 4$ (Schmitt, 2004). The pelvic peak acceleration for pelvis fracture is $73 \mathrm{~g}$ as reported by Zhu et al. (1993). This criterion was derived from side impact with cadavers and it is also used by Simms \& Wood, (2009) to indicate the pedestrian pelvic injury. The knees, especially in the case of a side impact, 
are under threat of bending. The maximum mediolateral bending angle according to van Rooij, (2003) is around 13 degrees.

Table 2: Injury analysis.

\begin{tabular}{|c|c|c|c|c|c|}
\hline & \multirow{2}{*}{$\mathrm{HIC}_{36}[-]$} & \multirow{2}{*}{ 3ms [g] } & \multirow{2}{*}{ Pelvis [g] } & \multicolumn{2}{|c|}{ Knee bending angle [deg] } \\
\hline & & & & Right leg & Left leg \\
\hline Injury limit & 1000 & 60 & 73 & \pm 12.7 & \pm 12.7 \\
\hline Robby $40 \mathrm{~km} / \mathrm{h}$ & 1483 & 66 & 80.6 & $26,-41$ & $14,-57$ \\
\hline
\end{tabular}

All tested injury criteria and their limit values are summarized in Table 2. It is obvious that the tested criteria exceed their limits. Figure 7 demonstrates the knees' movement during the impact and the confrontation with the limit values. In conclusion, the pedestrian suffers serious injuries in all controlled body parts.

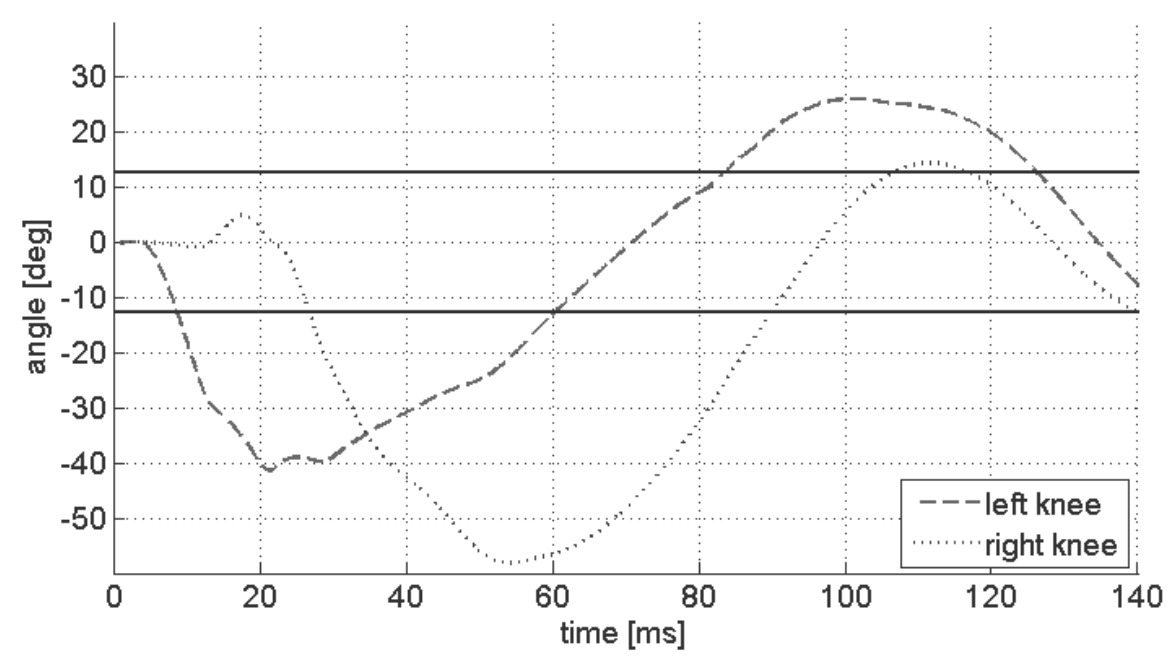

Figure 7: Pedestrian knee bending angles (dashed and dotted line) during the lateral impact and the injury limits (solid lines).

\section{CONCLUSION}

The previously developed rigid body based human model is validated in the full-scale pedestrian impact. Simulation results are compared to published cadaveric experimental data. Real car characteristics, including a detailed car profile, are used. All monitored body segments trajectories fall within the experimental corridors.

Despite the injury values only giving a general indication of the severity rather than a precise injury prediction, they perform as an appropriate tool in the case of rigid body based models. The presented injury analysis of the lateral impact in relatively low velocity $(40 \mathrm{~km} / \mathrm{h})$ indicates the serious pedestrian injuries to the head, thorax, pelvic area, and both knees. 


\section{ACKNOWLEDGEMENT}

The work is supported by the project CG911-044-150 of the Czech Ministry of Transport and by the John $\mathrm{H}$. and Amy Bowles Lawrence Foundation. Great thanks belong to ESI Group International.

\section{REFERENCES}

Haug, E., Beaugonin, M., Montmayeur, N., Marca, C., Choi, H.: 2003. Towards legal virtual crash tests for vehicle occupant safety design using human models. International Crashworthiness and Design Symposium (ICD03).

Haug, E., Choi, H.Y., Robin, S., Beaugonin, M.: 2004. Human models for Crash and impact simulation. Special volume of Handbook of numerical analysis, Vol. XII, (Editor P.G. Ciarlet) Elsevier, North Holland, pp. 231-670.

Hynčík L.: 2001. Rigid Body Based Human Model for Crash Test Purposes. Engineering Mechanics, Engineering Academy of the Czech Republic, Vol. 8, No. 5, pp. 1-6.

Hynčík, L., Nováček, V., Bláha, P., Chvojka, O., Krejčí, P.: 2007. On scaling of human body models. Applied and Computational Mechanics, University of West Bohemia, Pilsen, Vol. 1, No.1, pp. 63-74.

Hynčík, L., Číhalová, L., Kocková, H., Bláha, P., Beaugonin, M.: 2009. Virtual anthropometric human models for safety. Proceedings of International Society of Biomechanics, Cape Town, South Africa, 2009.

Ishikawa, H., Kajzer, J., Schroeder, G.: 1993. Computer Simulation of Impact Response of the Human Body in Car-Pedestrian Accidents. Paper No. 933129, Thirty-seventh Stapp Car Crash Conference Proceedings.

Kam, C. Y., Kerrigan, J., Meisser, M., Drinkwater, C., Murphy, D., Bolton, J., Arregui, C., Kendall, R., Ivarsson, J., Crandall, J., Deng, B., Wang, J. T., Kerlinge, Hahn, W.: 2005: Design of a Full-Scale Impact System for Analysis of Vehicle Pedestrian Collisions. Paper 2005-01-1875, Society of Automotive Engineers, Warrendale, PA.

Kerrigan, J. R., Murphy, D. B., Drinkwater, D.C., Kam, C.Y., Bose, D., Crandall, J.R.: 2005. Kinematic corridors for PMHS tested in full-scale pedestrian impact. University of Virginia Center for Applied Biomechanics, paper No. 05-0394.

Maňas J, Glac, V, Šefrhans, M.: 2009. Analýza dopravní nehodovosti za účasti zranitelných účastníků dopravy. Zpráva k řešení aktivity A 901 dílčího cíle DC 01 projektu Ministerstva dopravy č. CG911-044-150. MECAS ESI s.r.o., Plzeň.

Obermann, J., Kovanda, J.: 2009. Pedestrian Detection. Transactions on Transport Sciences, Ministry of Transport of the Czech Republic, Vol. 2, No. 3, pp. 128 - 133.

PAM-System Users Manual, Version 2009. 
Robbins, D. H.: 1983. Anthropometric Specifications for Mid-Sized Male Dummy, Volume 2. University of Michigan Transportation Research Institute (UMTRI), research report number UMTRI-83-53-2.

van Rooij, L.: 2003. The evaluation of the kinematics of the MADYMO human pedestrian model against experimental tests and the influence of a more biofidelic knee joint. $5^{\text {th }}$ MADYMO Users Meeting of the Americas.

Schmitt, K. U., Niederer, P., Walz, F.: 2004. Trauma Biomechanics, Introduction to Accidental Injury. Springer-Verlag, Germany.

Simms, C. K., Wood, D. P.: 2006. Pedestrian risk from cars and sport utility vehicles a comparative study. Proc. IMechE, Vol. 220 Part D: J. Automobile Engineering.

Simms, C. K., Wood, D. P.: 2009. Pedestrian and Cyclist Impact, A Biomechanical Perspective. Springer Science+Business Media, B.V.

Stammen, J., Barsan-Anelli, A.: 2001. Adaptation of a human body mathematical model to simulation of pedestrian/vehicle interactions. 4th MADYMO User's Meeting Of The America's, Detroit.

Zhu, J. Y., Cavanough, J. M., King A., I.: 1993. Pelvic biomechanical response and padding benefits in side impact based on cadaveric test series. SAE paper 933128.

European Commission - Road Safety:

http://ec.europa.eu/transport/road_safety/users/pedestrians/index_en.htm 